\title{
Clinical aspects of juvenile idiopathic arthritis: extended experience from Bangladesh
}

\author{
Shahana A Rahman*, Mohammad Imnul Islam, Manik Kumar Talukder \\ Bangabandhu Sheikh Mujib Medical University, Dhaka, Bangladesh
}

Email address:

shahana2pd@yahoo.com(S. A. Rahman)

\section{To cite this article:}

Shahana A Rahman, Mohammad Imnul Islam, Manik Kumar Talukder. Clinical Aspects of Juvenile Idiopathic Arthritis: Extended Experience from Bangladesh. American Journal of Clinical and Experimental Medicine. Vol. 1, No. 1, 2013, pp. 20-23.

doi: 10.11648/j.ajcem.20130101.14

\begin{abstract}
Objectives: To assess the different clinical aspects of JIA patients as well as the disease activity status during follow-up period. This study also compared its findings with the previous baseline study done in our country. Methodology: A prospective observational study carried out in the department of pediatrics, Bangabandhu Sheikh Mujib Medical University, Dhaka, Bangladesh during the study period of January 2004 to December 2012. A total of 415 patients according to ILAR criteria were enrolled in the study. Patients who completed a 2 year follow-up period were assessed for disease activity status according to Wallace criteria. Data was collected in a predesigned questionnaire. Results: Among the 415 cases, M: F ratio was approximately 2:1. Age range of the patients was 14 months to 16 years. Highest number of patients were present in the age group 11-16 years (49\%) followed by 6-10 years. The duration of illness was more than 12 months in the majority. Polyarticular RF negetive patients were most frequent (33\%), followed by persistent oligo-arthritis (28\%). Among the patients who completed at least 2 years of follow-up, $68 \%$ achieved remission, of them $51 \%$ maintained remission and $16.3 \%$ had relapse. Conclusion: Late diagnosis with long duration of disease was still common. Clinical profile of this study was almost similar to our previous study but differed from western JIA cases mainly in term of sex, subtypes and duration of illness. Majority of the patients went into remission. Wrong diagnosis was gradually decreasing and it seems that awareness about JIA is gradually increasing among the medical professionals in our country.
\end{abstract}

Keywords: Clinical Profile, Disease Activity Status, Remission, Relapse

\section{Introduction}

Juvenile idiopathic arthritis (JIA) is the most common chronic rheumatic illness in children and is a very important cause of short and long-term morbidity and disability. ${ }^{1}$ According to the International League Against Rheumatism (ILAR), JIA is defined as definite arthritis of unknown etiology that begins before the 16th birthday and persists for at least 6 weeks. ${ }^{2}$

It is reported that clinical presentation of JIA vary in different populations . ${ }^{3,4}$ A study done in India suggested that the clinical manifestations, age and sex distribution of JIA were different from various series reported from the USA, Canada, Spain and UK. ${ }^{5}$ One preliminary baseline study from Bangladesh reported that the clinical presentation of their JIA cases differed from western JIA cases mainly in terms of sex distribution, subtypes and late presentation. Late diagnosis with long duration of disease and deformities were also common in that study. ${ }^{6}$

With the current practice of early aggressive interventions and the development of new therapeutic agents, more children with JIA are likely to experience low levels of disease activity or even complete remission. ${ }^{7}$ The objective of this study was to assess the clinical profile of JIA patients among Bangladeshi children as well as the disease activity status during their follow up period. The study also aimed at comparing the findings of this study with the findings of the previous baseline study done in Bangladesh.

\section{Methodology}

This was a prospective observational study carried out in the pediatric rheumatology follow-up clinic run by the Department of pediatrics, Bangabandhu Sheikh Mujib Medical University (BSMMU), Dhaka from January 2004 
to December 2012. This study included all the patients, attending the pediatric rheumatology clinic, fulfilling the ILAR classification criteria. ${ }^{8}$

A total number of 415 patients were enrolled in this study. After obtaining informed consent from parents/attendants, data was collected in a questionnaire. The data included demographic information, a detailed history, clinical examination findings, relevant investigation and eye examination findings. While taking the history, more emphasis was given to relevant joint symptoms. Similarly, during examination, emphasis was given to the musculoskeletal system and the relevant aspects. Demographic information was recorded only at enrollment. But other parameters were assessed at enrollment and also during follow up. Follow up was done 4 weekly (for very ill patients) to 12 weekly (for inactive state patients), depending on the condition. All the patients were evaluated by an ophthalmologist with slit lamp for any evidence of uveitis.

Children with different subtypes of JIA who had been followed up for at least 2 years were evaluated for disease activity status including inactive disease, clinical remission and flares. The criteria adopted to define inactivity and clinical remission were proposed recently by Wallace et al which include: 1) no active arthritis in any joint; 2) no fever, rash, serositis, splenomegaly, or generalized lymphadenopathy attributable to JIA; 3 ) no active uveitis; 4) normal ESR or C-reactive protein; 5) a physicians global assessment on a visual analogue scale ranging from inactive to very severe, rated at the best score possible. ${ }^{9}$ In all the follow up visits data was also recorded according to Wallace criteria

\section{Results}

A total of 415 children were enrolled in this study. Among them $68 \%$ were male and $32 \%$ were female, M: F ratio being approximately $2: 1$. The age range of the patients was 14 months to 15 years. The highest number of patients were present in the age group of 11 to 16 years (49.1\%) followed by 6 to 10 years $(38.3 \%)$. Only $12.6 \%$ of patients were present in the age group of 1 to 5 years.

Duration of disease at presentation was more than 12 months in the majority (48.6\%). Only $18 \%$ of the patients had duration of disease of less than 6 months (Table-1).

According to ILAR criteria, the polyarticular RFnegative subtype was found as the most frequent (33\%) in this series. This was followed by oligoarticular persistent (28\%), systemic-onset JIA (15\%), enthesitis-related arthritis (13\%) and oligoarticular extended cases (5\%). Polyarticular RF positive was found among $6 \%$ cases in this series (Fig-1).

About $26 \%$ patients were presented to us with some previous diagnosis like rheumatic fever, septic arthritis and tubercular arthritis. Some remained undiagnosed during presentation (32\%). JIA was the initial diagnosis in about $36 \%$ patients in this series. Rheumatic fever was the initial diagnosis in $20.84 \%$ patients and they were on penicillin prophylaxis. Diagnosis of tubercular arthritis and septic arthritis (3.3\% and $2.2 \%$ ) was done mainly in monoarthritis patients (Table-II).These patients were also having antitubercular treatment and long term antibiotics.

Three hundred fifty-five JIA patients out of 415 completed their two years follow-up during the study period. Irrespective of the subtypes, about $32 \%$ patients did not achieve remission. About $68 \%$ patients fulfilled the remission criteria during their 2 years follow up period. Among them 51.5\% maintained remission and 16.3\% had relapse (one or multiple). Highest number of remission was found in the ERA sub type $(63.8 \%)$ followed by oligoarticular persistent cases $(60.2 \%)$. The highest number of persisting disease activity was found in systemic JIA (39.5\%) followed by RF positive polyarticular JIA (35.3\%). Maximum number of relapse occurred in systemic JIA cases (Table-III).

\section{Discussion}

This prospective observational study was carried out in a tertiary care hospital to assess the profile of JIA cases as well as to see the disease activity patterns during the follow up period. This study also compared its findings with the findings of the previously done preliminary baseline study in Bangladesh.

There were more males than females in the present study and $\mathrm{M}$ : $\mathrm{F}$ ratio was approximately 2:1 which was very similar to our previous study. ${ }^{6}$ Though it is well recognized that among JIA cases female always outnumber males, ${ }^{10}$ this study found a different result. Few studies done in India also reported consistent result as well. ${ }^{5,11}$ This finding might be explained by our socio-cultural background, where male children are given more care and are brought to the hospitals more frequently than female children.

Most of the patients presented to us in the age group of 11-16 years $(45.5 \%)$. The duration of the disease at presentation was long (more than 1 year) in the majority (48.6\%).This finding is almost consistent with our previous report where more than $50 \%$ of patients came to us with duration of disease of more than 1 year. ${ }^{6}$ Although, the finding was almost similar, we are still optimistic that the duration of illness at presentation is decreasing very slowly. Duration of disease was also higher in an Indian cohort consistent with the present study. ${ }^{5}$

While classifying sub types of JIA, poly-articular RF negative was found as the majority in this series (33\%). This finding is almost similar to our initial report, where more than $41 \%$ had polyarticular RF negative JIA. It is reported that oligoarticular JIA is the commonest type among the Caucasians in Europe, USA and Canada constituting more than half of JIA cases. ${ }^{10,12,13}$ Classification of patients into various subtypes according to ILAR criteria is not always easy particularly when patients are presented late. 
The reasons behind the polyarticular preponderance in our study and other Indian studies may be multi-factorial. Majority of our patients usually come with long duration of disease with very poor documents. Thus some of the extended oligoarthritis cases may be classified as polyarticular JIA. Another possibility is that the patients having more serious diseases (polyarticular cases usually have severe disease than oligoarticular cases) are likely to attend a tertiary hospital setting. The possibilities are further substantiated by the fact that majority $(60 \%)$ of the patients from a community based study reported from our center in Bangladesh had oligo-articular JIA. ${ }^{14}$ In that community based study sex ratio was also different, girl: boy ratio being about $2: 1$.

When we compared our present study with the previous preliminary one, we are very pleased to report only about $26 \%$ wrongly diagnosed cases in the present study. On the other hand, the diagnosis was wrong in more than $60 \%$ cases in our previous study. In the present study, more than $36 \%$ patients reported with correct diagnosis which was only $19 \%$ in the previous one. As wrong diagnosis was less common, diagnosis as rheumatic fever, tubercular arthritis and septic arthritis was also less. Moreover, about 32\% patients came to us undiagnosed, which was only $23 \%$ in the previous series. ${ }^{6}$ These findings may reflect increased awareness about JIA and other pediatric rheumatologic problems in our country.

When the disease activity status was analyzed, it was found that out of 355 patients who completed a minimum of 2 years follow up; about $68 \%$ patients achieved inactive disease status irrespective of sub-types of JIA. Among them, $51.5 \%$ patients maintained remission and about $16 \%$ had relapse (once or more) after remission (Table-III). It is reported that the percentage of patients with clinical remission or inactive disease at follow-up ranges from $40 \%$ to $60 \%$. These improvements are likely to be due to the positive impacts of recent therapeutic advances. ${ }^{7}$ Wallace et al in a study found that $89 \%$ episodes experienced inactive disease during their follow up and 40-60\% flared up after 2 years of remission.$^{15}$ Here, we are reporting a baseline data about the disease activity status among our JIA patients who completed their 2 years follow up. Episode wise data was not compiled and analyzed in this report. However, our results were more or less consistent with the published reports. ${ }^{7,15,16}$

In the present study, highest and lowest number of clinical remission was achieved among ERA patients and systemic JIA patients respectively. On the other hand highest number of relapse (once or more) occurred in systemic JIA patients (Table-III). So, it may be concluded that systemic JIA patients had the worst prognosis in this series. These findings are not consistent with the study done by Shenoi and Wallece ${ }^{16}$ where it was found that oligoarticular persistent cases were most likely and polyarticular RF positive cases were least likely to achieve remission.

\section{Conclusion}

From this tertiary hospital based study, it was found that long duration of disease with late diagnosis was still common in our country, though it was minimally less than the previous report. Wrong diagnosis was gradually decreasing. Clinical profile of this study was almost similar to our previous study, but differed from western JIA cases mainly in terms of sex distribution, subtypes of the disease and duration of illness. Thus it may be concluded that, awareness about JIA is slowly increasing among medical professionals of our country.

Table I. Duration of illness at presentation $(n=415)$

\begin{tabular}{ccc}
\hline Duration of illness & Number & Percentage \\
\hline 6 weeks to 6 months & 75 & $18.07 \%$ \\
7 months to 12 months & 139 & $34.4 \%$ \\
More than 12 months & 201 & $48.6 \%$ \\
Total & 415 & 100 \\
\hline
\end{tabular}

Table II. Diagnosis of JIA patients prior to presentation $(n=415)$

\begin{tabular}{ccc}
\hline Diagnosis & Number & Percentage \\
\hline JIA & 151 & 36.38 \\
Rheumatic Fever & 94 & 20.84 \\
Undiagnosed & 145 & 32.15 \\
Tubercular arthritis & 15 & 3.3 \\
Septic Arthritis & 10 & 2.2 \\
Total & 415 & 100 \\
\hline
\end{tabular}

Table III. Disease activity status of JIA patients $(n=355)$

\begin{tabular}{cccc}
\hline Types & $\begin{array}{c}\text { Disease active } \\
\text { Number (\%) }\end{array}$ & $\begin{array}{c}\text { Remission } \\
\text { Number (\%) }\end{array}$ & $\begin{array}{c}\text { Relapse } \\
\text { Number (\%) }\end{array}$ \\
\hline $\begin{array}{c}\text { Poly RF- ve } \\
(\mathrm{n}=115)\end{array}$ & $40(34.8)$ & $57(49.5)$ & $18(15.6)$ \\
$\begin{array}{c}\text { Poly RF +ve } \\
(\mathrm{n}=17)\end{array}$ & $6(35.3)$ & $7(41.2)$ & $4(23.5)$ \\
$\begin{array}{c}\text { Oligo-extended } \\
(\mathrm{n}=35)\end{array}$ & $10(28.6)$ & $18(51.4)$ & $7(20)$ \\
$\begin{array}{c}\text { Oligo-persistent } \\
(\mathrm{n}=98)\end{array}$ & $33(33.7)$ & $59(60.2)$ & $6(6.1)$ \\
$\begin{array}{c}\text { SOJIA } \\
(\mathrm{n}=43)\end{array}$ & $17(39.5)$ & $12(27.9)$ & $14(32.5)$ \\
$\begin{array}{c}\text { ERA } \\
(\mathrm{n}=47)\end{array}$ & $8(17)$ & $30(63.8)$ & $9(19.1)$ \\
$\begin{array}{c}\text { Total=355 } \\
\text { ER }\end{array}$ & $114(32 \%)$ & $183(51.5 \%)$ & $58(16.3 \%)$ \\
\hline
\end{tabular}




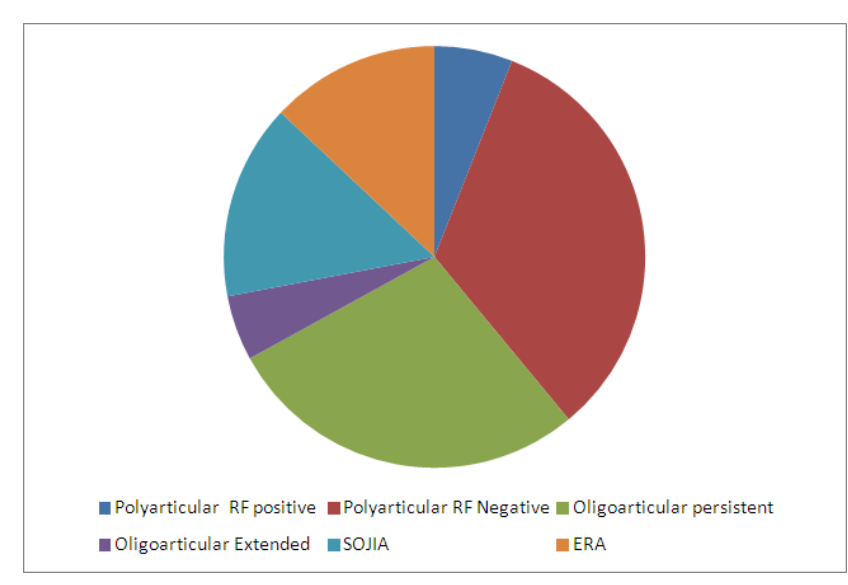

Figure 2. Sub types of JIA

\section{References}

[1] Jennifer EW, Norman TI. Juvenile idiopathic arthritis. Pediatr Clin N Am 2005; 52: 413-42.

[2] Hofer M, Southwood TR. Classification of childhood arthritis. Best Pract Res Clin Rheumatol 2002; 16, 379-89.

[3] Ramsey S, Bolaria R, Cabral D, Malleson P, Petty R. Comparison of Criteria for the Classification of childhood arthritis. J Rheumatol 2000; 27:1283-86.

[4] Merino R, De Inocencio J, Garcia-Consuegra J. Evaluation of ILAR classification criteria for juvenile idiopathic arthritis in Spanish children. J Rheutamol 2002:29: 2731-36.

[5] Kunjir V, Venugopalan A, Chopra A. Profile of Indian patients with juvenile onset chronic inflammatory joint disease using the ILAR classification criteria for JIA: a community based cohort study. The Journal of Rheumatology 2010; 37: 1756-62.

[6] Rahman SA, Islam M I, Hossain M, Talukder M K. Clinical presentation of juvenile idiopathic arthritis in Bangladesh: experience from a tertiary hospital. International Journal of
Rheumatic Disease 2008; 11:50-54.

[7] Ravelli A, Martini A. Remission in juvenile idiopathic arthritis. Clin Exp Rheumatol 2006; 24 (Suppl. 43):S105S110.

[8] Petty RE, Southwood TR, Manners P, Baum J, Glass DN, Goldenberg $\mathrm{J}$, et al. International League of Associations for rheumatology classification of juvenile idiopathic arthritis: $2^{\text {nd }}$ revision, Edmonton, 2001. J Rheumatol 2004; 31:390-92.

[9] Wallace CA, Ruperto N, Giannini EH; Childhood Arthritis and Rheumatology Research Alliance; Paediatric Rheumatology International Trials Organization; Paediatric Rheumatology Collaborative Study Group. Preliminary criteria for clinical remission for select categories of juvenile idiopathic arthritis. J Rheumatol 2004; 31:2290-4.

[10] Cassidy JT, Petty RE .Chronic arthritis in childhood. In: Cassidy JT, Petty RE, Laxer RM, Lindsley CB. Editors. Text Book of Pediatric Rheumatology, $6^{\text {th }}$ ed. Philadelphia: Saunders Elesvier; 2011. p 211-286.

[11] Agarwal A, Misra R. Juvenile chronic arthritis in India. It is different from that seen in the western countries. Rheumatol Int 1994; $14: 53-6$.

[12] Eveline YW, Heather A, Van MC, Rabinovich CE. Juvenile idiopathic arthritis. In: Kliegman RM, Stanton BF, Schor NF, Geme JWS, Behrman RE. Nelson Textbook of Paediatrics, $19^{\text {th }}$ ed. Philadelphia: Saunders; 2011. P 829-39.

[13] Boel A G. Juvenile arthrits- who gets it, where and when ?A review of current data on incidence and prevalence. Clin Exp Rheumatol 1999; 17: 367-374.

[14] Azam S, Dipti T, Rahman S. Prevalence and clinical pattern of juvenile idiopathic arthritis in a semi-urban area of Bangladesh. International Journal of Rheumatic Disease 2012; 15:116-20.

[15] Wallace CA, Huang B, Banderia M, Ravelli A, Giannini EH Patterns of clinical remission in select categories of juvenile idiopathic arthritis .Arthritis \& Rheum 2005; 52:3544-62.

[16] Shenoi S, Wallace CA. Remission in juvenile idiopathic arthritis: Current facts. Cur Rheumatol Rep 2010; 12: 80-86. 